\title{
Analisis Faktor Intrinsik Dan Ekstrinsik Motivasi Kerja Perekam Medis Dan Informasi Kesehatan Di Rumah Sakit
}

\section{Analysis of Intrinsic and Extrinsic Factors of Work Motivation of Medical Records and Health Information Staff at The Hospital}

\author{
Sri Lestari ${ }^{1}$ \\ Aisya Putri Pravitasari ${ }^{2}$ \\ Sugiyanto ${ }^{3}$
Jurusan Rekam Medis dan Informasi Kesehatan Poltekkes Kemenkes Semarang
Jl. Tirto Agung, Pedalangan, Banyumanik, Semarang
E-mail : kids.family@gmail.com

\begin{abstract}
While medical record staff working, they're not only doing their job but they also needs motivation. Good motivation expected to produce good performance of the staff in carrying out the tasks. The first survey in RSUD Ungaran showed that the lack of appreciation for the workers achievements make the workers become less motivated. The purpose of this research is to determine the work motivation factors of the medical record and health information staff in RSUD Ungaran, in terms of characteristic, extrinsic factor and intrinsic factor. The method that we used in this research is descriptive method, which describes the event under study, with a quantitative approach, which is defined as a positivism research method. The population in this research is all medical record staff in RSUD Ungaran. Total of 21 sheet of the questionnaire given to all respondents and returned as much as 20 sheets, one sheet left because the respondent was on leave. The results shows that the intrinsic factor is $76.25 \%$ and the extrinsic factor is $78.13 \%$, the age range of the respondents are between $41-65$ years old, with work period 18-40 years, the staff with last education as Medical Record Diploma as many as 7 people. High indicator are the work itself $(87.5 \%)$ and intrapersonal relationship (97.5\%). Our suggestions are to give appreciation or award to the employee at least saying congratulation to them. We also recommend RSUD Ungaran to repair the hospital management system facilities, it need to be fixed as soon as possible so the employee will be more enthusiastic at work. And offer a training or further education to the medical recorders who didn't graduated as Medical Record Diploma.
\end{abstract}

Keywords : intrinsic factor, extrinsic factor, work motivation, medical record staff

\begin{abstract}
Abstrak
Perekam medis dalam bekerja tidak hanya sekedar menjalankan tugas dan kewajibannya saja, namun mereka juga membutuhkan motivasi. Motivasi yang baik diharapkan mampu mendorong para perekam medis untuk menghasilkan kinerja yang baik pula dalam melaksanakan tugasnya. Survey awal di RSUD Ungaran menunujukkan bahwa penghargaan atau apresiasi terhadap prestasi pegawai masih kurang, sehingga hal ini menyebabkan para pegawai menjadi kurang termotivasi. Tujuan penelitian ini yaitu untuk mengetahui faktor motivasi kerja perekam medis dan informasi kesehatan di RSUD Ungaran, dilihat dari karakteristik, faktor ektrinsik dan instrinsik. Metode penelitian yang digunakan adalah metode deskriptif yaitu menggambarkan sebuah kejadian yang diteliti, dengan pendekatan kuantitatif yaitu yang diartikan sebagai metode penelitian yang bersifat positivisme. Populasi yang digunakan dalam penelitian ini adalah seluruh petugas rekam medis. Sebanyak 21 lembar kuesioner diberikan kepada seluruh responden dan tersisa satu karena responden sedang dalam
\end{abstract}


masa cuti. Hasil yang didapat adalah rata-rata faktor intrinsik mencapai $76.25 \%$ dan faktor ekstrinsik sebanyak 78.13\%, karakteristik umur petugas rata-rata 41-65 tahun, masa kerja 18-40 tahun, pendidikan terakhir DIII Rekam Medis sebanyak 7 orang. Indikator paling tinggi adalah Pekerjaan itu sendiri (87.5\%) dan hubungan intrapersonal (97.5\%). Saran dari kami agar diberikan apresiasi atau penghargaan kepada pegawai minimal dalam bentuk ucapan selamat. Dan sebaiknya dilakukan perbaikan fasilitas SIMRS dengan segera agar para petugas rekam medis menjadi lebih semangat dalam bekerja. Diperlukan juga pemberian pelatihan atau pendidikan lanjutan bagi pegawai rekam medis yang bukan merupakan lulusan dari DIII Rekam Medis.

Kata Kunci : faktor intrinsik, faktor ekstrinsik, motivasi kerja, petugas rekam medis.

\section{Pendahuluan}

Perekam medis perlu memperhatikan bagaimana keadaan dirinya ketika bekerja, karena dalam bekerja kita tidak hanya sekedar menjalankan tugas dan kewajiban kita namun kita juga memerlukan motivasi. Motivasi yang baik diharapkan mampu mendorong kita untuk menghasilkan kinerja yang baik pula dalam melaksanakan tugas. Motivasi adalah suatu set atau kumpulan perilaku yang memberikan landasan bagi seseorang untuk bertindak dalam suatu cara yang diarahkan kepada tujuan spesifik tertentu (Soeroso, 2002).

Terdapat dua faktor yang mampu mempengaruhi motivasi, yaitu faktor ekstrinsik dan faktor intrinsik. Faktor ekstrinsik adalah gambaran kebutuhan fisiologis individu yang diharapkan mampu untuk dipenuhi. Faktor ekstrinsik antara lain upah, jaminan pekerjaan, kondisi kerja, status, prosedur perusahaan, mutu supervisi, dan mutu hubungan pribadi antar rekan kerja. Sedangkan faktor intrinsik merupakan faktor yang apabila ada dalam pekerjaan tersebut, maka akan menggerakkan tingkat motivasi pribadi yang kuat sehingga dapat menghasilkan prestasi kerja yang baik. Contoh faktor intrinsik meliputi prestasi, pengakuan, tanggung jawab, peluang untuk maju, dan kepuasan kerja.

RSUD Ungaran mempunyai tujuan yaitu terwujudnya kerjasama yang baik dan harmonis serta meningkatkan kesejahteraan seluruh staf dan karyawan.
Tujuan tersebut menjadi landasan dasar bahwa setiap petugas diharapkan mempunyai kerjasama yang baik dengan antarprofesi medis maupun non-medis, manajemen, dan juga pada tingkatan sesama rekan kerja. Berdasarkan studi pendahuluan yang dilakukan melalui wawancara terhadap lima petugas rekam medis di RSUD Ungaran, diketahui bahwa belum ada perhatian atau apresiasi terhadap prestasi petugas, dan juga masih terdapat petugas yang datang terlambat. Hasil studi pendahuluan tersebut didukung dengan hasil penelitian yang dilakukan oleh Windari dan Kristijono (2016) tentang analisis ketepatan koding yang dihasilkan koder di rumah sakit yaitu faktor lain yang mempengaruhi kualitas ketepatan koding dalam bekerja adalah motivasi, kebutuhan penghargaan diri serta kurang mendapatkan perhatian dari pimpinan rumah sakit. Kebutuhan penghargaan diri yaitu respek dan pujian atas keberhasilan dan merasa dirinya berharga. Kebutuhan ini dipenuhi dengan mendapatkan penghargaan dan pengakuan atas pengetahuan, ketrampilan dan usaha kerasnya, penghargaan finansial, kenaikan gaji, bonus serta insentif sosial, seperti pelatihan. Tujuan penelitian ini adalah untuk mengetahui faktor ekstrinsik dan factor intrinsik motivasi kerja perekam medis dan informasi kesehatan di RSUD Ungaran. 


\section{Metode}

Jenis penelitian yang digunakan adalah survey deskriptif. Pada umumnya survey ini digunakan untuk membuat penilaian terhadap suatu kondisi yang sedang terjadi atau pada penyelenggaraan suatu program di masa sekarang. Peneliti menggunakan pendekatan kuantitatif yang diartikan sebagai metoda penelitian yang bersifat positivisme. Waktu yang dibutuhkan untuk melaksanakan penelitian ini yaitu selama dua bulan. Populasi dalam penelitian ini adalah petugas rekam medis yang bekerja di RSUD Ungaran. Teknik penarikan sampel menggunakan teknik total sampling yaitu seluruh petugas rekam medis di RSUD Ungaran yang berjumlah 21 orang. Metode pengumpulan data menggunakan kuesioner dan hasil kuesioner yang telah didapat tersebut diperkuat lagi dengan dilakukannya wawancara terhadap pertugas terkait. Pada skoring penghitungan jawaban kuesioner ditetapkan bahwa skor tertinggi diberi nilai 1 yaitu untuk jawaban "Ya" dan nilai 0 untuk jawaban "Tidak". Responden menjawab kuesioner dalam bentuk checklist. Analisis faktor intrinsik dan ekstrinsik dilakukan dengan menghitung rata-rata nilai yang diperoleh dari jawaban responden terhadap jumlah keseleruhan responden yang mengisi kuesioner. Selanjutnya dilakukan wawancara dari hasil jawaban yang terendah maupun yang tertinggi.

\section{Hasil dan Pembahasan}

Penelitian dilaksanakan dengan pembagian kuesioner kepada 21 responden Dari 21 lembar kuesioner yang dibagikan, lembar kuesioner yang kembali hanya sebanyak 20 lembar saja dikarenakan 1 orang responden sedang dalam masa cuti.
Responden yang berumur 41-65 tahun sebanyak 11 orang (55\%), sedangkan responden yang berumur 18-40 tahun sebanyak 9 orang (45\%). Berdasarkan usia, rata-rata perekam medis dan informasi kesehatan di RSUD Ungaran termasuk ke dalam kategori golongan tua. Hal tersebut mengacu pada kategori umur menurut WHO. Frekuensi responden yang berjenis kelamin perempuan sebanyak 15 orang $(75 \%)$ dari 20 responden, 5 orang $(25 \%)$ lainnya berjenis kelamin laki - laki.

Responden yang memiliki pendidikan berlatar belakang DIII Rekam Medis dan Informasi Kesehatan sebanyak 7 orang (35\%), sedangkan 13 orang lainnya memiliki pendidikan yang tidak sesuai dengan profesi perekam medis. Dari hal tersebut maka didapatkan analisis bahwa RSUD Ungaran masih belum memenuhi kriteria berdasarkan Permenpan nomor 30 tahun 2013 tentang jabatan fungsional dan angka kreditnya BAB XI pasal 32 ayat (3) yaitu Rumah Sakit tipe C mempunyai formasi 30 orang terampil dan 6 ahli.

Masa kerja perekam medis RSUD Ungaran yang mempunyai pengalaman bekerja selama 18-40 tahun sebanyak 8 orang $(40 \%)$, sedangkan responden yang bekerja selama 12-17 tahun sebanyak tiga orang (15\%), 06-11 tahun sebanyak 5 orang $(25 \%)$ dan responden yang mempunyai masa kerja $<5$ tahun sebanyak 4 orang (20\%). Semakin lama seorang berada dalam satu pekerjaan maka kecil kemungkinan untuk mengundurkan diri (Robbins dan Judge, 2008).

Status kepegawaian dari responden terdiri dari dua, yaitu Pegawai Negeri Sipil (PNS) atau biasa disebut juga sebagai pegawai tetap dan pegawai non-PNS yang merupakan pegawai BLUD. 16 dari 20 responden $(80 \%)$ mempunyai status sebagai PNS. 
Tabel 3.1 Hasil rata-rata perolehan indikator motivasi kerja pada Perekam Medis di RSUD Ungaran

\begin{tabular}{llll}
\hline \multicolumn{1}{c}{ Faktor Intrinsik } & \multicolumn{1}{c}{$\%$} & \multicolumn{1}{c}{ Faktor Ekstrinsik } & \multicolumn{1}{c}{$\%$} \\
\hline Prestasi & 58.75 & Kondisi Kerja & 63.75 \\
\hline Penghargaan Orang Lain & 71.67 & Kebijakan Rumah Sakit & 96.25 \\
\hline Tanggungjawab & 80 & Kualitas Supervisi & 82.5 \\
\hline Keinginan untuk Maju & 83.33 & Hubungan Interpersonal & 97.5 \\
\hline Pekerjaan itu sendiri & 87.5 & Gaji & 70 \\
\cline { 2 - 4 } & & Keamanan Kerja & 58.75 \\
\hline Rata-rata & 76.25 & Rata-rata & 78.13 \\
\hline
\end{tabular}

Pada tabel diatas dapat dilihat bahwa motivasi kerja perekam medis pada dasarnya tinggi dan rata-rata untuk faktor ekstrinsik $(78.13 \%)$ lebih besar dari faktor intrinsik (76.25\%). Hubungan antar pribadi memperoleh presentase tinggi yaitu 97.5. Hardjana (2003) menuliskan pada bukunya bahwa manusia bergantung pada orang lain, saling berbagi dan bekerjasama untuk kelestarian hidup karena apabila hubungan ini buruk maka akan mengalami stress dan dapat mengganggu kesehatan fisik. Pekerjaan itu sendiri (the work itself) menempati kedudukan faktor intrinsik yang paling tinggi yaitu $87.5 \%$. Berdasarkan pernyataan bahwa pekerjaan sesuai dengan latar belakang pendidikan yang masuk kategori sedang yaitu $70 \%$. Hal ini berdasarkan karakteristik pendidikan pegawai perekam medis RSUD Ungaran yang rata-rata pendidikannya SMA/SLTA, walaupun begitu pimpinan juga mendukung adanya pelatihanpelatihan, pelatihan yang telah dilakukan oleh perekam medis RSUD Ungaran antara lain, pelatihan pengarsipan, peningkatan kualitas koder rumah sakit, pelatihan manajemen komunikasi kesehatan dan ICD-10, workshop Case-Mix INA-CBG, dan pelatihan Pokja Manajemen Komunikasi Informasi (MKI). Kendala yang dialami oleh pimpinan rekam medis adalah beberapa dokter sulit untuk dikonfirmasi, fasilitas yang kurang memadai untuk mendukung kinerja antara lain adalah kurangnya sirkulasi udara pada ruang kerja yang menyebabkan petugas menjadi kurang nyaman dan merasa gerah ketika sedang bekerja dan juga pada fasilitas Sistem Informasi Manajemen Rumah Sakit (SIMRS) terlihat bahwa pada pernyataan fasilitas sistem informasi memperoleh kategori sedang (60\%) dengan skor 12. Berdasarkan wawancara terhadap pimpinan rekam medis, hal tersebut dikarenakan adanya kendala pada SIMRS yang belum dapat memenuhi kebutuhan manajemen. Kendala lain yang dialami oleh pimpinan adalah terbatasnya pegawai yang mempunyai pendidikan satu linier dengan pekerjaan dimana komposisi pegawai berdasarkan pendidikan terakhir, hanya ada 7 (tujuh) pegawai yang mempunyai latar belakang pendidikan DIII Rekam Medis dan Informasi Kesehatan, akan tetapi distribusi pegawai yang berlatar belakang pendidikan DIII Rekam Medis dan Informasi Kesehatan belum tersebar merata khususnya dibagian koding.

\section{Simpulan dan Saran}

Perolehan prestasi yang berkaitan dengan pekerjaannya sebagai perekam medis mendapat perolehan persentase paling rendah sehingga akan lebih baik jika perekam medis lebih aktif dalam memperoleh perstasi baik prestasi dari luar (organisasi profesi) maupun dari rumah sakit sehingga pihak manajemen rumah sakit dapat menciptakan kegiatan-kegiatan 
yang bersifat memberikan penghargaan kepada perekam medis. Kondisi lain yang mempengaruhi motivasi kerja adalah kondisi sirkulasi udara yang kurang nyaman dan kondisi SIMRS yang kurang memenuhi kebutuhan manajemen sehingga sebaiknya fasilitas sistem informasi manajemen rumah sakit segera ditangani agar lebih mempersingkat waktu penyelesaian pekerjaan dan memudahkan pegawai dalam melaksanakan pekerjaannya dan perlu diadakannya perbaikan sirkulasi udara. Pegawai dengan lulusan DIII Rekam Medis masih terbatas sehingga pendidikan lanjutan ke jenjang DIII Rekam Medis perlu diberikan bagi pegawai rekam medis yang memiliki latar belakang tidak linier atau tidak sesuai dengan bidang rekam medis dan juga perlu diadakan pelatihan terkait rekam medis agar para pegawai lebih termotivasi dalam bekerja

\section{Ucapan Terima Kasih}

Terima kasih kepada Peneliti 2, Sdri. Aisya Putri Pravitasari dan Peneliti 3, Bapak Sugiyanto, S.Pd. M.App.Sc. yang telah berperan serta dalam penulisan penelitian ilmiah ini. Tak lupa kepada orangtua serta rekan - rekan dosen dan pengelola Jurusan Rekam Medis dan Informasi Kesehatan yang telah mendukung penyelesaian penulisan ini.

\section{Daftar Pustaka}

Buchbinder, Sharon B and Nancy H. Shanks. 2014. Manajemen Pelayanan Kesehatan. Alih bahasa, Palupi Widyastuti, Estu Tiar. Jakarta : EGC.

Danim, Sudarwan. 2008. Kinerja Staf dan Organisasi. Bandung : Pustaka Setia.

Garmelia, Elise dan Erkadius. 2010. "Pengenalan Organisasi dan Supervisi", dalam Pedoman MIK disarana Pelayanan Kesehatan. 2010. Jakarta : UI Press.
Hardjana, Agus M. 2003. Komunikasi Intrapersonal dan Komunikaasi Interpersonal. Yogyakarta : Kanisius.

Hasibuan, Malayu S.P. 2003. Manajemen Sumber Daya Manusia. Jakarta : PT. Bumi Aksara.

Hatta, Gemala R. 2010. Pedoman Manajemen Informasi Kesehatan disarana Pelayanan Kesehatan. Ed 2. Jakarta : UI Press.

Keputusan Menteri Pendayagunaan Aparatur Negara. 2002. Jabatan Fungsional Perekam Medis dan Angka Kreditnya. Nomor 135. Jakarta.

Keputusan Menteri. 2007. Standar Profesi Perekam Medis dan Informasi Kesehatan. Jakarta.

Dirjen YanmedLubis, Elynar. 2009. Pengaruh Karakteristik Individu dan Motivasi Ekstrinsik terhadap kinerja Dokter dalam Kelengkapan Pengisian Rekam Medis Rawat Inap Di Rumah Sakit PT Perkebunan Nusantara IV (Persero) Tahun 2008. Medan. Tesis Master Kesehatan USU : tidak diterbitkan.

Mangkunegara,Anwar Prabu. 2009. Manajemen Sumber Daya Manusia. Bandung: PT. Remaja Rosdakarya.

Mangkuprawira, S. dan A.V. Hubeis. 2007. Mananjemen Sumber Daya Manusia. Bogor: Ghalia Indonesia.

Moorhead, Gregory dan Ricky W. Griffin. 2013. Perilaku Organisasi : Manajemen Sumber Daya Manusia dan Organisasi, terj. Diana Angelica. Jakarta : Salemba Empat.

Notoatmodjo, Soekidjo. 2010. Metodologi Penelitian Kesehatan. Ed. Rev.Jakarta : Rineka Cipta.

Pambudi, Ranu. 2016. Tinjauan Faktor Intrinsik dan Ekstrinsik Motivasi Kerja Petugas Rekam Medis di Rumah Sakit Harum Sisma Medika Tahun 2016. Tugas Akhir Diploma Rekam Medis : Universitas Esa Unggul.

Peraturan Menteri PAN RB. 2013.Jabatan Fungsional dan Angka Kreditnya. Nomor 30. Jakarta : Menpanrb. 
Robbins, Stephen P dan Timothy A. Judge. 2008. Perilaku Organisasi. Ed. 12. Penerj, Diana Angelica. Jakarta : Salemba Empat.

Satrianegara, M. Fais dan Sitti Saleha. 2009. Buku Ajar Pelayanan Organisasi dan Manajemen Pelayanan Kesehatan serta Kebidanan. Jakarta : Salemba Medika.

Soeroso, Santoso. 2002. Manajemen Sumber Daya Manusia di Rumah Sakit : Suatu Pendekatan Sistem. Jakarta : EGC.

Sugiyono (2017), Metode Penelitian Kuantitatif, Kualitatif, dan R\&D Bandung: Alfabeta, CV.

Suharsimi Arikunto. 2010. Prosedur Penelitian, Suatu Pendekatan Praktik. Jakarta Rineka Cipta. 